\title{
Experience with more than 100 total artificial heart implants
}

\author{
Jack G. Copeland, MD, ${ }^{\mathrm{a}}$ Hannah Copeland, MD, ${ }^{\mathrm{a}}$ Monica Gustafson, MD, ${ }^{\mathrm{b}}$ Nicole Mineburg, RN, CCTC, \\ Diane Covington, RN, ${ }^{d}$ Richard G. Smith, MSEE, ${ }^{d}$ and Mark Friedman, MD $^{c}$
}

\begin{abstract}
Objective: The SynCardia Total Artificial Heart (SynCardia Systems Inc, Tucson, Ariz) has been used as a bridge to cardiac transplantation in 930 patients worldwide and in 101 patients in our program. Our experience with SynCardia Total Artificial Heart implantation documents its indications, safety, and efficacy.
\end{abstract}

Methods: Data regarding preoperative condition, mortality, and morbidity have been reviewed and analyzed.

Results: From January 1993 to December 2009, 101 patients had bridge to transplant procedures with the SynCardia Total Artificial Heart. Ninety-one percent of cases were Interagency Registry for Mechanically Assisted Circulatory Support profile 1, and the remaining $9 \%$ of cases were failing medical therapy on multiple inotropic medications. The mean support time was 87 days (median, 53 days; range, 1-441 days). Pump outputs during support were 7 to $9 \mathrm{~L} / \mathrm{min}$. Adverse events included strokes in $7.9 \%$ of cases and take-back for hemorrhage in $24.7 \%$ of cases. Survival to transplantation was $68.3 \%$. Causes of death of 32 patients on device support included multiple organ failure (13), pulmonary failure (6), and neurologic injury (4). Survival after transplantation at 1,5 , and 10 years was $76.8 \%, 60.5 \%$, and $41.2 \%$, respectively. The longest-term survivor is currently alive 16.4 years postimplantation.

Conclusions: These patients were not candidates for left ventricular assist device therapy and were expected to die. The SynCardia Total Artificial Heart offers a real alternative for survival with a reasonable complication rate in appropriate candidates who otherwise might have been assigned to hospice care. (J Thorac Cardiovasc Surg 2012;143:727-34)

Total artificial heart (TAH) implantation as a bridge to transplantation was attempted in $1969^{1}$ and $1981 .^{2}$ In 1985, we implanted the Jarvik-7 (Symbion Inc, Salt Lake City, Utah) in a patient for the first successful bridge to transplant followed by long-term survival. ${ }^{3}$ Since that era, approximately 15,000 mechanical circulatory support devices have been implanted in patients, including more than 930 SynCardia Total Artificial Heart (TAH-t) (SynCardia Systems Inc, Tucson, Ariz) implants worldwide. The SynCardia TAH-t became the only TAH ever approved by the Food and Drug Administration (FDA) in 2004 and by the Centers for Medicare \& Medicaid Services in 2008. There are now 20 TAH implanting centers in Europe, 15 TAH implanting centers in the United States, and $1 \mathrm{TAH}$ implanting center in Australia. An additional 18 centers in Europe and 12 centers in the United States are in the process

\footnotetext{
From the Department of Surgery, ${ }^{\text {a }}$ University of California San Diego, San Diego, Calif; Departments of Surgery ${ }^{\mathrm{b}}$ and Medicine, ${ }^{\mathrm{c}}$ University of Arizona, Tucson, Ariz; and University Medical Center, ${ }^{\mathrm{d}}$ Tucson, Ariz.

Disclosures: Hannah Copeland reports equity ownership and service as a board member for Syncardia systems. The other authors have nothing to disclose with regard to commercial support.

Read at the 37th Annual Meeting of the Western Thoracic Surgical Association, Colorado Springs, Colorado, June 22-25, 2011.

Received for publication May 29, 2011; revisions received Nov 14, 2011; accepted for publication Dec 6, 2011; available ahead of print Jan 16, 2012.

Address for reprints: Jack G. Copeland, MD, University of California San Diego, 200 W. Arbor Drive, MC 8892, San Diego, CA 92103 (E-mail: jackcope3@gmail. com).

$0022-5223 / \$ 36.00$

Copyright (c) 2012 by The American Association for Thoracic Surgery doi:10.1016/j.jtcvs.2011.12.002
}

of credentialing. The increase in activity has been based on several factors, including the availability this year in Europe and Australia of a 6-kg driver that permits hospital discharge. Before that, the majority of implants in the world were supported by 36 large $180-\mathrm{kg}$ consoles. There were no other drivers. Patients have now spent more than 20,000 days out of hospital with the SynCardia TAH-t, and 1 patient surviving as an outpatient for 1327 days recently underwent successful transplantation.

Another factor that may be responsible for the increased number of implants has been recognition of the limitations of left ventricular assist device (LVAD) therapy. Recent publications establish the predictive value of risk scales such as the Lietz-Miller Score, ${ }^{4}$ SOFA score, ${ }^{5}$ HeartMate II risk score, ${ }^{6}$ right ventricular failure score, ${ }^{7}$ and Muenster score. $^{8}$ These scores have shown that patients with Interagency Registry for Mechanically Assisted Circulatory Support (INTERMACS) profile 1, "crash and burn,"9 may have a several-fold increased risk with LVADs. In the multicenter trial with the SynCardia TAH-t,${ }^{10}$ we analyzed 43 prognostic factors by univariate and multivariate analyses and compared these with multivariate analyses for LVADs and biventricular assist devices (BiVADs). We found that a history of smoking and a prothrombin time greater than 16 seconds were the only predictors of a bad outcome for TAH-t recipients at any time postoperatively. ${ }^{11}$ Factors that had been found to be predictors of mortality with LVADs in the risk factor scoring systems included thrombocytopenia, ventilator support, renal dysfunction, 


\begin{tabular}{|c|c|}
\hline \multicolumn{2}{|c|}{ Abbreviations and Acronyms } \\
\hline BiVAD & $=$ biventricular assist device \\
\hline BSA & $=$ body surface area \\
\hline ECMO & $\begin{aligned}= & \text { extracorporeal membrane } \\
& \text { oxygenation }\end{aligned}$ \\
\hline FDA & $=$ Food and Drug Administration \\
\hline INTERI & $\begin{aligned}= & \text { Interagency Registry for } \\
& \text { Mechanically Assisted } \\
& \text { Circulatory Support }\end{aligned}$ \\
\hline LVAD & $=$ left ventricular assist device \\
\hline NYHA & $=$ New York Heart Association \\
\hline PTFE & $=$ polytetrafluoroethylene \\
\hline TAH & $=$ total artificial heart \\
\hline TAH-t & $=$ temporary total artificial heart \\
\hline
\end{tabular}

hepatic dysfunction, previous surgery, and right-sided heart failure. ${ }^{4-8}$ These were not significant predictors for the TAH. A previously published comparative study from our center documented survival to transplantation of $75 \%$ for TAH recipients, $57 \%$ for LVAD recipients, and $38 \%$ for BiVAD recipients. ${ }^{12}$ The working hypothesis is that the TAH rescues patients who would have a higher risk with an LVAD.

Finally, some situations seem best suited for TAH, including failed cardiac transplantation (acute or chronic), massive myocardial infarction, acquired ventricular septal defect, diffuse mural thrombosis, failed Fontan, severe hypertrophic cardiomyopathy, and catastrophic intraoperative cardiac damage.

Three programs have implanted more than 100 TAHs in patients: La Pitie Salpetrier has implanted more than 200 TAHs,${ }^{13}$ Bad Oyenhausen (L. Arusoglu, MD, personal communication, October 2011) has implanted more than 100 TAHs, and our program has implanted more than 100 TAHs. Another source of data on TAH results is available from INTERMACS,${ }^{14}$ but at this early stage of enrollment into the registry it may be biased by the large number of recent start-up programs in the United States and by the learning curve effect, particularly with respect to patient selection. This has not been true in all new programs, for instance, the Virginia Commonwealth University has a series of 27 consecutive TAH survivals to transplantation (M. Hess, MD, and V. Kasirajan, MD, personal communication, October 2011).

Our series started in 1985 with the Jarvik-7 and in 1993 with the SynCardia TAH-t in an investigational device exemption study aimed at obtaining FDA approval. The SynCardia TAH-t history, use, sizing, function, indications, and anticoagulation, and our previous results up to 55 implants have been reported. ${ }^{15-17}$ We present the experience with the SynCardia TAH-t from 1993 to 2009.

\section{MATERIALS AND METHODS}

The current study began in January 1993 and ended in December 2009. It includes 101 consecutive patients from University Medical Center (Tucson, Ariz), with 65 patients previously reported as part of a multiinstitutional investigational device exemption study from 1993 to $2002 .^{10}$ Thirty-six more patients from University Medical Center were added between 2002 and 2009. Indications and exclusions for implantation in that study have been reported. ${ }^{10}$ Inclusion criteria were as follows: patient eligible for cardiac transplantation, New York Heart Association (NYHA) functional class IV, body surface area (BSA) 1.7 to $2.5 \mathrm{~m}^{2}$ or T10 distance from sternum to anterior vertebral body by computed tomography scan of $10 \mathrm{~cm}$ or greater, either cardiac index of $2 \mathrm{~L} / \mathrm{min} / \mathrm{m}^{2}$ or less and systolic pressure $90 \mathrm{~mm} \mathrm{Hg}$ or less and central venous pressure $18 \mathrm{mmHg}$ or more, or on 2 of the following: dopamine $10 \mu \mathrm{g} / \mathrm{kg} / \mathrm{min}$ or greater, dobutamine $10 \mu \mathrm{g} / \mathrm{kg} / \mathrm{min}$ or greater, epinephrine $2 \mu \mathrm{g} / \mathrm{kg} / \mathrm{min}$ or greater, other drugs at maximum levels, intra-aortic balloon pump, or cardiopulmonary bypass. Exclusion criteria were as follows: use of any ventricular assist device, pulmonary vascular resistance of 8 Wood units or greater (640 dynes/ $\mathrm{sec} / \mathrm{cm}^{5}$ ), dialysis in previous 7 days, serum creatinine $5 \mathrm{mg} / \mathrm{dL}$ or greater, cirrhosis with total bilirubin $5 \mathrm{mg} / \mathrm{dL}$ or greater, and cytotoxic antibody $10 \%$ or greater. After the completion of that study, we liberalized our criteria, accepting some patients for implantation who were too sick to meet the "eligible for cardiac transplantation" criteria.

A polytetrafluoroethylene (PTFE) neopericardium was constructed to cover the TAH in 70 of these patients. ${ }^{18}$ The rationale was to facilitate explantation. The implantation technique has been reported. ${ }^{19}$ The same anticoagulation strategy, including multiple tests and combined anticoagulation and antiaggregant therapies, was used in all patients. ${ }^{16}$

Adverse events were defined according to the FDA investigational device exemption trial ${ }^{10}$ and have been published. ${ }^{20}$ They are essentially the same as those published by INTERMACS. ${ }^{21}$ The definitions of some of the events were broad. For instance, "bleeding" included perioperative use of 8 units or more of packed red blood cells, any reoperation for bleeding, any postoperative thoracic drainage of more than $200 \mathrm{~mL} / \mathrm{h} 4$ hours or more postoperatively, and any transfusion of 3 units or more of blood within a 24 -hour period after the first 48 postoperative hours. Neurologic events included any transient ischemic attack, cerebral vascular event or seizure, any abnormal cerebral imaging study, and any other cause of neurologic deficit (eg, ischemic damage from cardiac arrest). Stroke is defined as a neurologic deficit lasting more than 24 hours. Infection is defined as a positive culture or clinical sepsis with negative culture. Infections were defined as serious if they were related to death or delayed transplantation.

\section{RESULTS}

This institutional review board-approved study began in 1993 with our first transplant of the SynCardia TAH-t, called the "CardioWest TAH." The last patient included in the series underwent transplantation in December 2009. The longest-term survivor is currently alive 16.4 years postimplantation. All transplantations were performed at the University Medical Center in Tucson, Arizona. Demographics are shown in Table 1. There were 101 patients with a mean age of 48 years (median, 52 years; range, 14-70 years). Eighty-five percent were male, and $75 \%$ were white. Patients had an average weight of $86 \mathrm{~kg}$ and a BSA of $2.05 \mathrm{~m}^{2}$. Nine patients had a BSA of $1.77 \mathrm{~m}^{2}$ or less. Forty-one patients were on mechanical ventilation, 26 patients were on mechanical circulatory support, 26 patients had experienced a recent cardiac arrest, and 4 patients were on extracorporeal membrane oxygenation. SynCardia 
TABLE 1. Demographics and baseline characteristics

All patients $(\mathrm{N}=\mathbf{1 0 1})$

Age at implant (y)

$\mathrm{n}$

Mean (SD)

Median

Min, Max

Gender

Male

Female

Ethnicity

African American

White

Hispanic

Native American

NYHA class

IV

N/A

Missing

INTERMACS status

1

$1 \mathrm{~A}$

2

$2 \mathrm{~A}$

Inotropes

Yes

No

Missing

Weight (kg)

$\mathrm{n}$

Mean (SD)

Median

Min, Max

Height $(\mathrm{cm})$

n

Mean (SD)

Median

Min, Max

BSA $\mathrm{m}^{2}$

$\mathrm{n}$

Mean (SD)

Median

Min, Max

Systolic blood pressure

$\mathrm{n}$

Mean (SD)

Median

Min, Max

Diastolic blood pressure

n

Mean (SD)

Median

Min, Max

Sodium

n

Mean (SD)

Median
All patients $(\mathrm{N}=\mathbf{1 0 1})$

101

48.5 (12.56)

52.0

14,70

$86(85.1 \%)$

$15(14.9 \%)$

$5(5.0 \%)$

$76(75.2 \%)$

$18(17.8 \%)$

$2(2.0 \%)$

$94(93.1 \%)$

$1(1.0 \%)$

$6(5.9 \%)$

$64(63.4 \%)$

$28(27.7 \%)$

$7(6.9 \%)$

$2(2.0 \%)$

$94(93.1 \%)$

$3(3.0 \%)$

$4(4.0 \%)$

89

$85.76(14.47)$

88.00

$53.0,118.6$

88

177.23 (8.80)

178.50

152.4, 195.0

93

$2.05(0.20)$

2.08

1.6, 2.5

79

93.4 (16.18)

92.0

58, 142

78

$56.8(9.34)$

55.0

36,83

96

130.8 (5.92)

131.0
TABLE 1. Continued

All patients $(\mathrm{N}=101)$

Min, Max

115,152

Creatinine

n

98

Mean (SD)

Median

$1.71(0.80)$

1.60

$0.4,4.5$

Total bilirubin

$\mathrm{n}$

Mean (SD)

Median

Min, Max

BNP

n

Mean (SD)

Median

Min, Max

Albumin

n

Mean (SD)

Median

Min, Max

Pre-albumin

n

Mean (SD)

Median

Min, Max

91

2.02 (1.19)

1.60

$0.4,6.5$

8

$1947.9(1292.61)$

1874.0

91, 3606

72

3.19 (0.60)

3.10

$1.8,4.5$

11

13.63 (5.23)

14.00

$6.9,23.0$

Platelets

$\mathrm{n}$

Mean (SD)

Median

Min, Max

Lactate

n

Mean (SD)

Median

Min, Max

RA

n

Mean (SD)

Median

Min, Max

PCWP

$\mathrm{n}$

Mean (SD)

Median

Min, Max

Cardiac index

n

Mean (SD)

Median

89

217.9 (100.57)

198.0

23, 587

17

2.31 (2.16)

1.90

$0.8,10.0$

19

$15.6(6.02)$

14.0

4, 26

69

30.8 (8.90)

30.0

4, 54

71

$1.90(0.48)$

1.80

Min, Max

$0.9,3.0$

NYHA, New York Heart Association; INTERMACS, Interagency Registry for Mechanically Assisted Circulatory Support; BSA, body surface area; $P C W P$, pulmonary capillary wedge pressure; $S D$, standard deviation; $B N P$, B-type natriuretic peptide; $R A$, right atrium; $N / A$, not available. 
TABLE 2. Adverse events during 24 patient years of support in 101 patients

\begin{tabular}{|c|c|c|}
\hline Adverse event & No. $(\%)$ & Timing postimplantation \\
\hline \multicolumn{3}{|l|}{ Neurologic } \\
\hline Total & $16(15.8 \%)$ & \\
\hline Stroke & $8(7.9 \%)$ & $\begin{array}{l}5 \text { events by } 9 \mathrm{~d}, 3 \text { events thereafter } \\
(0.125 \text { strokes/patient year } \\
\text { after the first } 9 \mathrm{~d})\end{array}$ \\
\hline No event & $85(84.2 \%)$ & \\
\hline \multicolumn{3}{|l|}{ Bleeding } \\
\hline Total & $43(42.6 \%)$ & \\
\hline Reoperations & $25(24.7 \%)$ & $\begin{array}{l}11 \text { in first } 24 \mathrm{~h} \text {, mean time to } \\
\text { take-back } 4.2 \mathrm{~d} \text { (range, } 0-25)\end{array}$ \\
\hline No event & $58(57.4 \%)$ & \\
\hline \multicolumn{3}{|l|}{ Infection } \\
\hline Total & $64(63.4 \%)$ & $\begin{array}{l}50 \% \text { of infections were in the first } \\
30 \mathrm{~d}\end{array}$ \\
\hline No event & $37(36.6 \%)$ & \\
\hline \multicolumn{3}{|l|}{ Peripheral emboli } \\
\hline Total & $8(7.9 \%)$ & 3 at $<7 \mathrm{~d}, 5$ at $38-286 \mathrm{~d}$ \\
\hline No event & $93(92 \%)$ & \\
\hline
\end{tabular}

TAH-t outputs were 7 to $9 \mathrm{~L} / \mathrm{min}$ with central venous pressures of $10 \mathrm{~mm} \mathrm{Hg}$ or less. At explantation, we found that the PTFE neopericardium decreased adhesion formation and the "skin to recannulation time" at explantation to 15 to 45 minutes.

Preimplantation, $93 \%$ of patients were in NYHA functional class IV. Among the remaining 7 patients, an NYHA classification was not found on chart review, but on review of their records we found that all were rapidly deteriorating with 6 patients on multiple inotropes and in multiple organ failure and 1 patient with catastrophic cardiac damage during a reoperation for endocarditis of an infected aortic root conduit. Ninety-one percent of patients were INTERMACS profile 1 (crash and burn), $64 \%$ of patients were INTERMACS profile 1 , and $28 \%$ of patients were INTERMACS profile 1A ("A" signifies additional risk from ventricular tachycardia or ventricular fibrillation). Among the other 9 patients, 2 were INTERMACS profile $2 \mathrm{~A}$ and 7 were INTERMACS profile 2 . There were 5 ischemic cardiomyopathies and 1 restrictive and 1 congenital post-Fontan and Blalock-Taussig shunt. All patients were failing on high-dose inotropes, but none had high-dose pressor agents. Ninety-three percent of patients were receiving inotropes. In the 7 patients who were not receiving inotropes, 4 had catheterization or acute infarction emergencies ( 1 with a ruptured left ventricle), 1 had an unrepairable aortic root failure to wean from cardiopulmonary bypass, and 2 were chronic cardiac transplant recipients with advanced coronary vasculopathy, ischemic cardiomyopathy, and progressive unresponsive congestive heart failure. Other preimplant variables were similar to those previously reported. ${ }^{10,12}$
Adverse events are listed in Table 2. Neurologic complications were seen in 16 patients $(15.8 \%)$, and 8 of these were embolic events $(7.9 \%)$. Among these, 5 occurred by day 9 . The remaining 3 events were on days 77,150 , and 204. Thus, during the 24 patient years of support, only 3 strokes were seen while patients were on chronic support and chronic anticoagulation (0.125 events per patient year). Four patients experienced chronic deficits, and 4 patients had resolution of symptoms and no neurologic residual. The other complications included the incidental finding of lesions on head computed tomography scans with no known associated symptom in 3 patients, ischemic damage from cardiac arrest in 2 patients, transient ischemic attacks in 2 patients, and 1 episode of severe air embolism. Eightyfive patients $(84.2 \%)$ had no neurologic complication of any kind. Among the 8 patients with embolic strokes, 3 had notable infections; 1 died of sepsis on the fifth postimplant day, 1 had a protracted bout of mediastinitis involving the prosthetic ventricles and requiring open chest therapy, and $1 \mathrm{had}$ an infected inlet valve of the left ventricle that led to a device change after 11 months.

A broad definition of "bleeding" resulted in the complication being noted in 43 patients $(42.6 \%)$. There were 25 mediastinal explorations $(24.7 \%)$ for hemorrhage. Eleven take-backs were in the first 24 hours postimplant, the remainder were within 25 days (mean, 4.2 days; range, $0-25$ days for all tack-backs). Eleven of these "take-back" cases (44\%) died within 5 days to 1 month after implantation. Eighteen other patients met the definition of bleeding, including 6 by virtue of the quantity and timing of blood transfusions, 4 from gastrointestinal bleeding, and the remaining 8 from various other bleeding sites (ie, epistaxis, vitreous, hemothorax, intracranial, and pericardial). Fifty-eight patients had no bleeding complication.

Sixty-four patients $(63.4 \%)$ had infections that were treated. The lungs and urinary tract were the most common sites. Three patients had clinical mediastinitis. One patient survived long term to transplantation after reoperation, debridement, and irrigation and is still alive 4 years later. The other 2 patients died; one of these patients was a young postpartum patient with cardiomyopathy who had failed on Thoratec BiVAD support (Thoratec Corp, Pleasanton, Calif) and was switched to the TAH, and the other patient had a massive hemorrhagic myocardial infarction with Crohn's disease sent with an intra-aortic balloon pump who had significant postimplantation bleeding and developed Proteus mirabilis mediastinitis. One patient had device endocarditis with methicillin-resistant Staphylococcus aureus. He survived and was hemodynamically and otherwise stable after TAH change-out. Support was withdrawn because he had experienced multiple strokes. One other notable infection was hemorrhagic Clostridium difficile colitis and sepsis that resolved after medical treatment with intravenous 


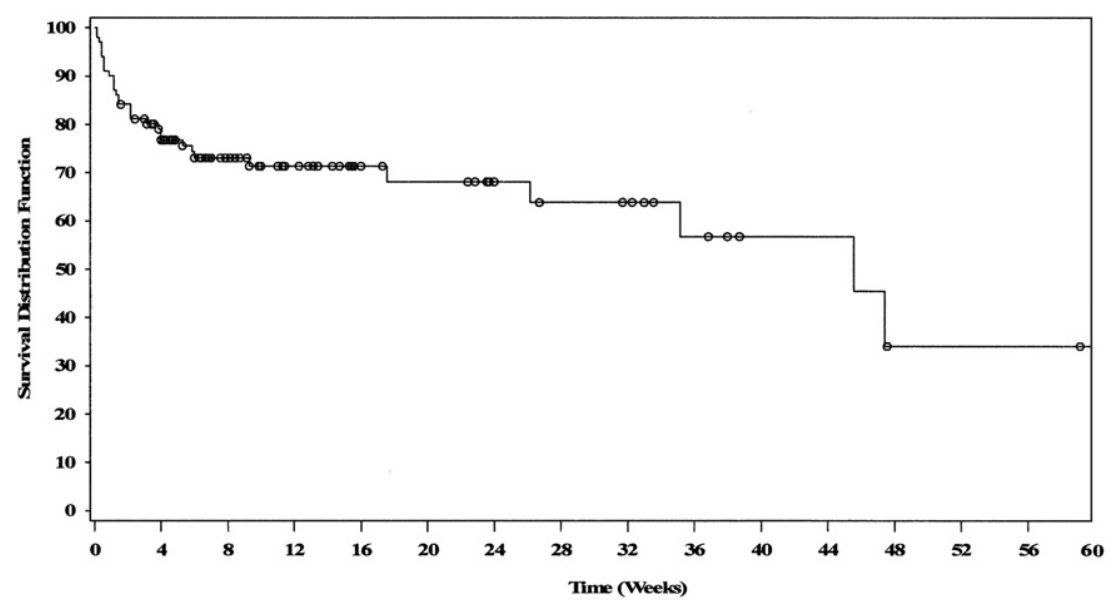

FIGURE 1. Survival to transplant is defined as time in weeks from date of device implantation to death before heart transplant. Patients are censored at the time of transplantation if they are still alive (circles).

metronidazole (Flagyl; Pfizer, Inc, New York, NY), oral vancomycin, and vancomycin enemas.

Peripheral emboli were documented in 8 patients in the following locations: celiac artery (1), spleen (2), superior mesenteric artery (1), kidney (2), and retina (2). Among the 6 patients with visceral emboli, 4 died. Four of these events were in the first week postimplantation.

Two patients died as the result of catheter entrapment of a central line in the tricuspid valve; 1 patient had a peripherally inserted central catheter line, and 1 patient had a central venous internal jugular line. In both cases, the end result was irreversible brain damage from device arrest.

Mean support time was $87 \pm 94.8$ days (median of 53 days, minimum of 1 day, maximum of 441 days). Survival to transplantation (the proportion surviving for a given time while awaiting transplantation) is shown in Figure 1. Sixty-nine patients $(68.3 \%)$ survived to transplantation. Post-transplant survival for the 69 patients who survived to transplantation is shown in Figure 2. Time zero is the explant-transplant operation. One-year survival was $76.8 \%$, and 5-year survival was $60.5 \%$. At the 10 -year survival mark, $41.2 \%$ were alive (18 patients). Overall survival refers to the fate of all patients who received implants. The overall survival at $1,5,10$, and 15 years was $55.4 \%$ (56 patients), $42.6 \%$ (35 patients), $28.1 \%$ (18 patients), and $26.1 \%$ (3 patients), respectively.

There were 32 deaths on device support. The competing outcomes analysis graph (Figure 3) demonstrates that $70 \%$ of the deaths were in the first 14 days and $90 \%$ were within 40 days after implantation, with 3 additional deaths over the next 231 days. Causes of death were multiple organ failure (13), pneumonia or pulmonary edema (6), sepsis (5), neurologic injury (4, including 1 stroke, 1 hypoxic damage from hypotension, and 2 intracranial hemorrhage), pancreatic abscess (1), small intestinal ischemia (1), disseminated intravascular coagulopathy (1), and disseminated coccidioidomycosis (1).

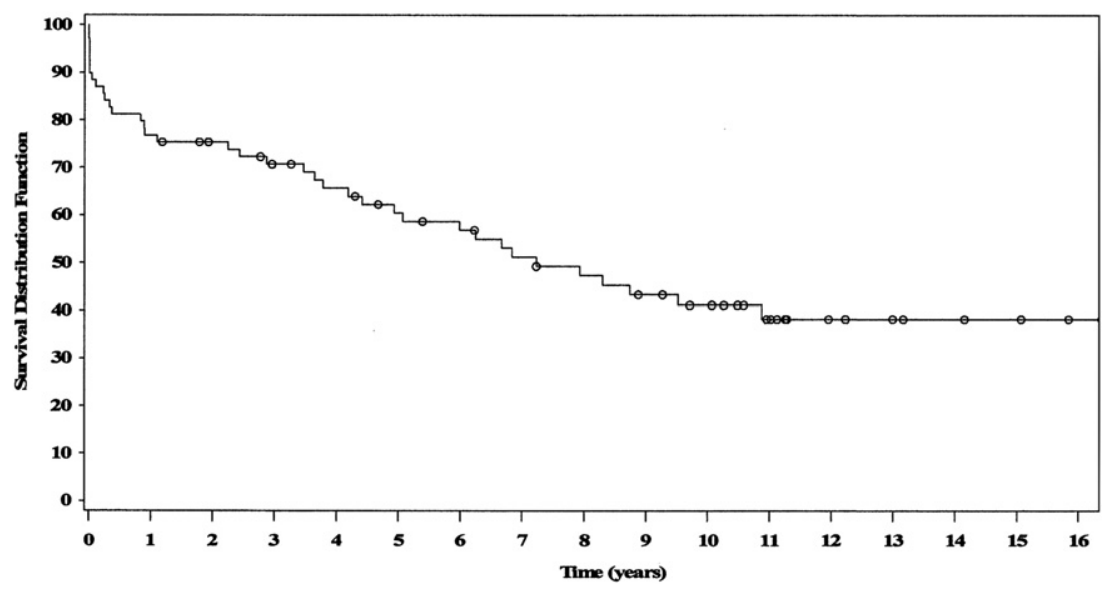

FIGURE 2. Post-transplant survival is defined as time in years from date of transplant to death. Only patients who have received a heart transplant are included in this figure. Censored patients (circles). Patients still alive are censored as of March 1, 2011. 


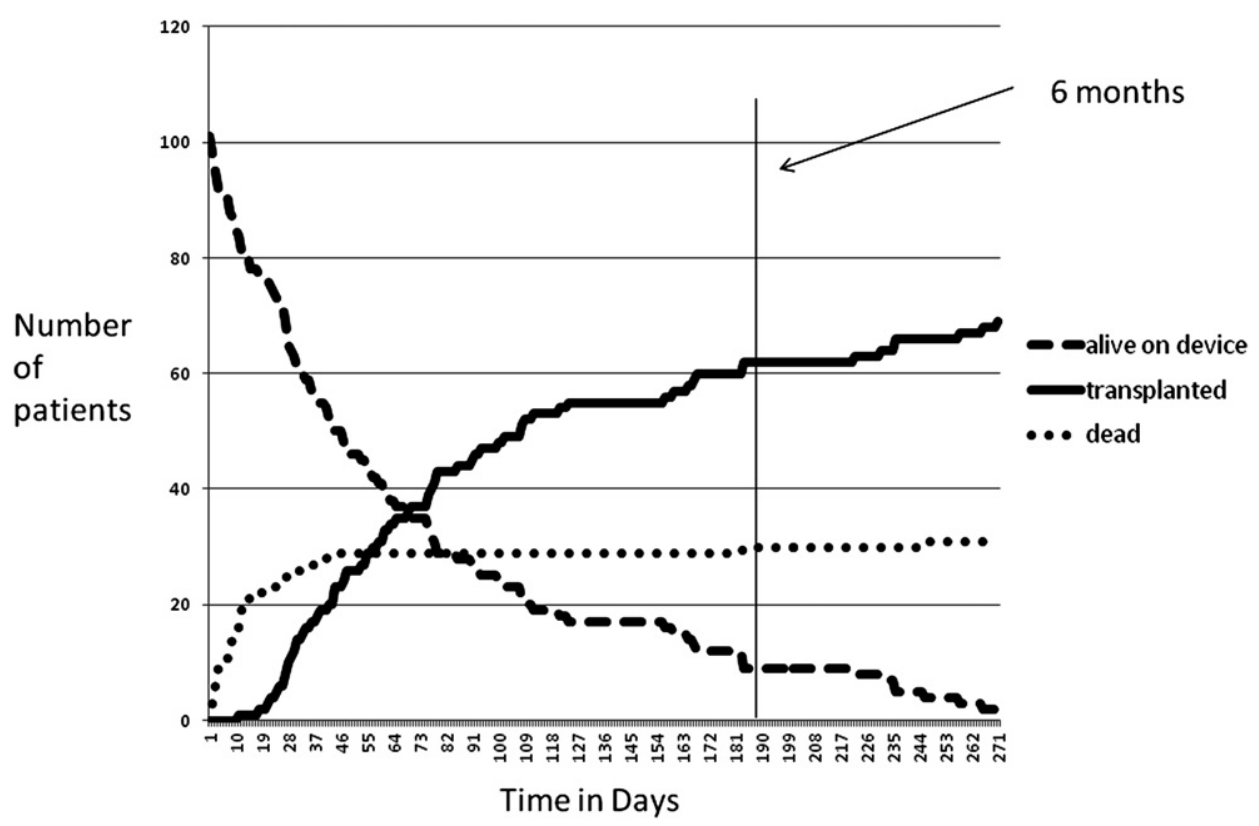

FIGURE 3. Competing outcomes analysis for total artificial heart in 101 patients.

\section{DISCUSSION}

As documented in this study, the TAH controls the circulation on the right and left sides, decreasing the central venous pressure, increasing the systemic pressure, and providing a cardiac output (7-9 L/min). The TAH weighs $160 \mathrm{~g}$ and displaces $400 \mathrm{~mL}$, and thus fits most adults with dilated hearts. Explantation is facilitated by creation of a neopericardium of PTFE at the time of implantation. ${ }^{17}$ Undisputed indications include failed cardiac transplantation, acute or chronic, massive myocardial infarction, acquired ventricular septal defect, diffuse mural thrombosis, failed Fontan, severe hypertrophic cardiomyopathy, and catastrophic intraoperative cardiac damage.

Other indications, such as severity of illness, rapidity of decompensation, inadequacy of medical therapies to stabilize the patient, and extent of multiorgan dysfunction, are continuous variables that create controversy and debate. Many arguments are made about the survival of the patient, such as finances, quality of life, medical therapy for device, assumed device durability, device-specific complications, and donor heart availability. In the end, we believe that saving the patient, especially when he/she is mortally ill, is most important. Further, we believe that our experience documents the salvage of patients who are outside of the therapeutic range of LVADs as defined by currently used risk prediction scores. ${ }^{4-8}$ This hypothesis is supported by a report comparing multivariate analysis of risk factors for other devices with the TAH. ${ }^{11}$ It is also supported by a study comparing outcomes with the TAH, LVAD, and BiVAD. ${ }^{12}$

Continuous-flow devices have now replaced pulsatile LVADs, ${ }^{22}$ and registry information is accumulating. More support for our hypothesis may be found in a recent review of the INTERMACS Registry. ${ }^{14}$ For primary LVAD implantation, it documents independent risk factors, including older age, higher bilirubin, higher right atrial pressure, and cardiogenic shock. Further, the authors found that the percentage of patients with INTERMACS 1 profile who are treated with LVADs is decreasing. They concluded that, "This likely reflects a recognition of the higher early mortality associated with implementation of mechanical circulatory support (LVADs) in the throes of cardiogenic shock."

Risk stratification and comparison of independent risk factors are indirect evidence of efficacy. More direct evidence does not exist. However, on the basis of current information, there is a legitimate place for the TAH use in crash and burn cases and it is the device of choice for some patients.

There is no doubt about the severity of illness in the patients in this study. NYHA functional status was IV, INTERMACS profile was 1 or $1 \mathrm{~A}$, and use of inotropes was universal. Another marker for degree of illness is that most of the postimplant deaths were early. A number of these patients were too sick for the TAH. A sicker group has not been defined. Yet, the survival numbers are reasonable. Sixty-eight percent of patients have survived to transplantation, and $77 \%$ survived post-transplantation. In a previous study, matched historical controls all died or underwent transplantation within 7 weeks. ${ }^{10}$ Also in that study, which included 65 patients from our center, the survival to transplantation was $80 \%$ with the TAH. Selection criteria were strictly enforced, and "compassionate use" cases were censored. 
Accruing 36 more patients over the period from 2003 to 2009 and including all patients from the FDA study have reduced survival to transplantation by $12 \%$, perhaps because we have not censored any patients. Thus, this report is a true accounting of all consecutive patients from 1993 to 2009.

One limitation of chart review databases such as ours is that they rely on written documentation; consequently, a few patients are not classified by functional status, not all have preimplant hemodynamic monitoring, and many do not have adequate data for calculating risk using one of the many scales. ${ }^{4-8}$ Another limitation is that emergencies often limit preimplant data acquisition.

Contraindications for implantation included chronic cardiac cachexia, advanced physiologic age, chronic failure of end organs incompatible with recovery, anticipated to be impossible to recover to transplant candidate status, and judged to have inadequate mediastinal size for the TAH.

Adverse events, including stroke in $8 \%$, reoperation in $24.7 \%$, device infection in $2.9 \%$, and peripheral embolism in $7.9 \%$, were serious but acceptable in a group of critically ill patients. Causes of death on device support were not surprising with most secondary to multiple organ failure (13). Other causes included pneumonia (6), sepsis (5), and neurologic (4).

\section{CONCLUSIONS}

There is a real clinical need for TAH support to rescue select patients with INTERMACS 1 profile from advanced life-threatening cardiac failure. There are also a number of specific scenarios that can best be treated with a TAH. The option for out-of-hospital care decreases cost, improves quality of life, and provides a long-term support option. None of the patients in this study were on outpatient device support. However, as more portable consoles become available and more centers are trained, the financial burden of obligatory inpatient care will be removed and more patients will be able to receive this therapy. From this single-center inpatient experience, we expect that more lives will be saved in the future.

\section{References}

1. Cooley DA, Liotta D, Hallman GL, et al. Orthotopic cardiac prosthesis for two staged cardiac replacement. Am J Cardiol. 1969;24:723-30.

2. Cooley DA. Staged cardiac transplantation, a report of three cases. Heart Transplant. 1982;1:145-53.

3. Copeland JG, Levinson MM, Icenogle TB, et al. The total artificial heart as a bridge to transplantation. JAMA. 1986;256:2991-5.

4. Lietz K, Long JW, Kfoury AG, et al. Outcomes of LVAD implantation as DT in the post-REMATCH era. Implications for patient selection. Circulation. 2007; 116:497-505.

5. Shahzad K, Li Q, Akashi H, et al. Degree of end organ damage as a predictor of outcomes after mechanical circulatory support device implantation-a more quantitative assessment. J Heart Lung Transplant. 2011;30(4S):S32.

6. Cowger J, Sundareswaran K, Rogers JG. The HeartMate II Risk Score: predicting survival in candidates for left ventricular assist support. J Heart Lung Transplant. 2011;30(4S):S31.
7. Matthews JC, Koelling TM, Pagani FD, Aaronson KD. The right ventricular failure risk score: a pre-operative tool for assessing the risk of right ventricular failure in LVAD candidates. J Am Coll Cardiol. 2008;51:2163-72.

8. Klotz S, Vahlhaus C, Riehl C, et al. Pre-operative prediction of post-VAD implant mortality using easily accessible clinical parameters. J Heart Lung Transplant. 2010;29:45-52.

9. Stevenson L, Pagani FD, Young JB, et al. Intermacs profiles of advanced heart failure: the current picture. J Heart Lung Transplant. 2009;29:535-41.

10. Copeland JG, Smith RG, Arabia FA, et al. Cardiac replacement with a total artificial heart as a bridge to transplantation. N Engl J Med. 2004;351:359-67.

11. Copeland JG, Smith RG, Bose RK, et al. Risk factor analysis in bridge to transplantation with the CardioWest Total Artificial Heart. Ann Thorac Surg. 2008;85: 1639-44.

12. Copeland JG, Smith RG, Arabia FA, et al. Comparison of the CardioWest TAH, the Novacor LVAS, and the Thoratec VAD in bridge to transplantation. Ann Thorac Surg. 2001;71(Suppl):S92-7.

13. LePrince P, Bonnet N, Rama A, et al. Bridge to transplant with the Jarvik-7 (CardioWest) total artificial heart: a single center 15 year experience. J Heart Lung Transplant. 2003;22:1296-303.

14. Kirklin JK, Naftel DC, Kormos RL, et al. Second Intermacs Annual Report: more than 1000 primary left ventricular assist implants. J Heart Lung Transplant. 2010;29:1-10.

15. Copeland JG, Dowling RD, Tsau PH. Total artificial hearts. In: Frazier $\mathrm{OH}$ Kirklin JK, eds. ISHLT Monograph Series 1. Philadelphia: Elsevier; 2006. p. 105-25.

16. Zimmerman H, Copeland JG, Aquila L, Smith RG. Total artificial heart. In Selke FW, del Nido PJ, Swanson SJ, eds. Sabiston and Spencer Surgery of the Chest. Philadelphia: Saunders-Elsevier; 2010. p. 1525-32.

17. Copeland JG, Arabia FA, Tsau PH, et al. Total artificial hearts: bridge to transplantation. Cardiol Clin. 2003;21:101-13.

18. Copeland JG, Arabia FA, Smith RG, Covington D. Synthetic membrane neopericardium facilitates total artificial heart explantation. J Heart Lung Transplant. 2001;20:654-6.

19. Arabia FA, Copeland JG, Pavie A, Smith RG. Implantation technique for the CardioWest total artificial heart. Ann Thorac Surg. 1999;68:698-704.

20. Copeland JG, Arabia FA, Banchy ME, et al. The CardioWest total artificial heart bridge to transplantation: 1993 to 1996 national trial. Ann Thorac Surg. 1998;66: 1662-9.

21. Interagency Registry for Mechanically Assisted Circulatory Support. Appendix A: Adverse event definitions. In: INTERMACS manual of operations. Version 2.3. Oct 30, 2008:1-5.

22. Slaughter MS, Rogers JG, Milano CA, et al. Advanced heart failure treated with continuous-flow left ventricular assist device. N Engl J Med. 2009;361:1-11.

\section{Discussion}

Dr Hari Mallidi (Stanford, Calif). When you boil the study down to its essence, it is basically a case series of poor quality from an epidemiologic standpoint in terms of guiding further future therapy, but it is a case series of approximately 100 patients treated with INTERMACS class 1 status treated with TAH over a period of 15 to 20 years. The devil is really in the details, and unfortunately the details were not really provided in the talk or the article.

There are really no data presented to convince the reader that in fact these patients are not eligible for LVAD. Do you have data concerning right ventricular function, pulmonary artery pressure, right ventricular systolic work index, or any sort of measure of right ventricular function or dysfunction at the time of implant?

Dr Hannah Copeland. We do. We looked at all the pressures and in our article referred to all of those publications. These data have been reported by Copeland and colleagues. ${ }^{10}$ Right atrial pressure was $20 \mathrm{~mm} \mathrm{Hg}$, pulmonary artery systolic pressure was $55 \mathrm{~mm} \mathrm{Hg}$, mean pressure was $44 \mathrm{~mm} \mathrm{Hg}$, and wedge pressure was $30 \mathrm{~mm} \mathrm{Hg}$. There was no difference in this current experience from that previously published. Further, as noted in the article, of 
101 patients, 56 were failing on some other form of mechanical support, had just had a cardiac arrest, or were failing on extracorporeal membrane oxygenation (ECMO). We also point out data from the literature that clearly shows LVAD recipients with multisystem organ failure have proven not to do well, and this forms the basis for predictive scales that document poor outcomes in highrisk LVAD recipients. For instance, a Lietz-Miller score in the 20 s predicts a $30 \%$ 1-year survival with LVAD support. All of our patients had multisystem organ failure or pathologic and anatomic reasons for total heart replacement.

Dr Mallidi. In general, our experience has shown that patients with elevated pulmonary artery pressures for the most part need LVAD therapy alone. Their right ventricles can be managed with inotropes or a temporary assist device to removal of the device or weaning from inotropic therapy with just LVADs.

There is no cohort for comparison. Do you have any data of the other ventricular assist device recipients at your center with respect to those who just received LVADs or BiVADs but not necessarily a TAH?

Dr H. Copeland. Contemporary experience with other devices at the same institution was published comparing it with the TAH. ${ }^{12}$ Briefly, survival was best with the TAH, followed by LVAD and then BiVAD. At our institution, more than 350 devices were implanted, including more than 150 LVADs, 82 BiVADs, and 15 right ventricular assist devices during the time of our reported TAH series. We did experience a 2-year time period when the TAH was not available and incurred high mortality rates attempting to salvage the same patient population with LVADs or BiVADs.

Dr Mallidi. There were certain groups of patients in your study who were not eligible for traditional ventricular assist devices. These included those with transplant failure, chronic or acute rejection, hypertrophic cardiomyopathy, or complex congenital anomalies. How many patients with the TAH have those indications for the device versus just the crash and burn case?

Dr H. Copeland. The majority were crash and burn cases. There were a few failed Fontan operations, 1 peripartum cardiomyopathy, and several intraoperative cardiac disasters that could only be resolved with a TAH, and then as previously mentioned and noted in the article, 26 patients were failing on a device (mainly LVADS), 26 patients had just experienced cardiac arrests, and 4 patients were failing ECMO. The rest were emergency placements.

Dr Mallidi. The most recent patients with INTERMACS report class 1 status had an overall survival of approximately $80 \%$ at 3 months. There was obviously a difference in survival between those who just received an LVAD and those who received a BiVAD, and according to the latest INTERMACS report, the TAH seems to have a survival in between the BiVAD and LVAD recipients, but class 1 patients are class 1 patients; they are crash and burn. The philosophy at many ventricular assist device centers has changed from maximal support with devices for these patients to immediate minimally invasive or less-invasive approaches to promote end-organ recovery before a more definitive treatment. During the last 1.5 years at Stanford, we have probably had approximately 15 crash and burn cases that were managed with temporary percutaneous devices or ECMO as a bridge to another device. What we found is 3 patients did not survive. Of the remaining 12, only 6 actually ended up receiving a ventricular assist device of any kind, and of those 6 only 2 ended up with a temporary right ventricular assist device and the rest just had LVAD therapy. This experience is probably being recapitulated at many other centers. What this study represents is a philosophy that has fallen out of favor at many centers in terms of the sicker the patient the greater the support that needs to be administered immediately.

Dr H. Copeland. The INTERMACS database, as mentioned in our article, for the TAH reflects the learning curve because a large number of centers are starting their TAH experience, and often patient selection in this situation focuses on patients who we would categorize as "compassionate need." Therefore, I disagree with your comment first of all.

In regard to how far you want to go with these patients, I will tell you this. I am a new mother of 6 months, and I am beyond hypervigilant for all of my patients. I have a great respect for life. I would hope that your comments do not reflect any less respect.

It is unfortunate if they (INTERMACS 1 cases) end up at your center and you do not treat them and instead send them to hospice. Using ECMO as a bridge to decision is valid and has been used by our program many times. ECMO and low-flow $(5 \mathrm{~L} / \mathrm{min})$ temporary devices may be inadequate to reverse advanced pathophysiology and therefore mislead surgeons and physicians and only serve as a pathway to patient death.

Dr Joseph Cleveland (Aurora, Colo). This patient population remains challenging with regard to durable device implantation and outcomes. We have just published in The Journal of Heart and Lung Transplantation our analysis of the INTERMACs database looking at BiVAD versus LVAD recipients. The outcomes are clearly inferior for the BiVAD recipients, and it gets down to again not the pump but the population. This patient group is extremely difficult. They are extremely high risk, and I think we need a better paradigm than implantable durable pumps. This strategy of BiVAD or TAH is just not going to result in good outcomes for this patient population and in particular for the INTERMACs level 1 cases. Our center has moved away from placing durable pumps in these patients and toward ECMO or other short-term assist device strategies. It is incredibly difficult to sometimes walk away from people, but at the same time we are going to be the group faced with responsibly using this technology and making sure that the technology remains viable. We cannot be operating on patients who are unsalvageable to attempt heroic operations with $\mathrm{Bi}$ VADs or artificial hearts because the data do not justify this practice. 